\title{
Kode Biru pada Pasien Sepsis di RSUP Prof. Dr. R. D. Kandou selang Juni 2018 sampai Juli 2019
}

\author{
${ }^{1}$ Daniel Rawis \\ ${ }^{2}$ Diana Ch. Lalenoh \\ ${ }^{2}$ Mordekhai L. Laihad
}

${ }^{1}$ Program Studi Pendidikan Dokter Fakultas Kedokteran Universitas Sam Ratulangi Manado
${ }^{2}$ Bagian Anestesiologi dan Terapi Intensif Fakultas Kedokteran
Universitas Sam Ratulangi Manado
Email: rdaniel1116@gmail.com

\begin{abstract}
Code blue is an emergency code used by hospitals throughout the world for handling emergency cases such as cardiac and pulmonary arrest. The code blue has to be announced immediately whenever someone is diagnosed as heart or respiratory attack; therefore, the hospital prepares a special team for implementation of this code. Sepsis is an inflammatory response of severe infection that can cause organ damage and even death. This study was aimed to determine the code blue in septic patients at Prof. Dr. R. D. Kandou Hospital Manado. This was a retrospective and observational study conducted at the Medical Record Installation of Prof. Dr. R. D. Kandou Hospital Manado. Samples were code blue patients diagnosed as sepsis during the period of June 2018 to July 2019. There were 34 septic patients as samples. The highest number/percentages of the samples were, as follows: ages of $>50$ years in 29 patients $(72.5 \%)$, female sex in 22 patients $(55 \%)$, response time $<5$ minutes in 33 patients (97\%), and death <24 hours after the code blue in 34 patients (100\%). In conclusion, with response time less than 5 minutes, the code blue mortality rate among septic patients was still high which was $100 \%$ within the first 24 hours.
\end{abstract}

Keywords: code blue, sepsis

\begin{abstract}
Abstrak: Kode biru adalah suatu kode darurat yang digunakan rumah sakit di seluruh dunia untuk penanganan kasus darurat seperti henti jantung dan paru. Kode biru harus segera dimulai kapan saja seseorang ditemukan dengan serangan jantung atau pernapasan sehingga dibentuk tim khusus oleh rumah sakit. Sepsis merupakan respon inflamasi dari infeksi berat yang dapat menyebabkan kerusakan organ hingga kematian. Penelitian ini bertujuan untuk mengetahui kode biru pada pasien sepsis di RSUP Prof. Dr. R.D. Kandou Manado. Penelitian dilakukan di Instalasi Rekam Medik RSUP Prof. Dr. R. D. Kandou Manado. Jenis penelitian ialah observasional retrospektif. Sampel penelitian ialah pasien kode biru di RSUP Prof. Dr. R. D. Kandou Manado dengan diagnosis sepsis yang memenuhi kriteria inklusi pada data rekam medik periode Juni 2018 sampai Juli 2019. Hasil penelitian mendapatkan jumlah total 34 pasien. Jumlah/persentase tertinggi dari pasien setelah dilakukan tindakan kode biru didapatkan pada usia $>50$ tahun yaitu 29 orang $(72,5 \%)$; jenis kelamin perempuan yaitu 22 orang (55\%); response time $<5$ menit yaitu 33 orang $(97 \%)$; dan pasien yang meninggal dunia $<24$ jam yaitu 34 orang $(100 \%)$. Simpulan penelitian ini ialah dengan response time $<5$ menit, angka kematian pasien sepsis dengan kode biru masih tetap tinggi yaitu mencapai $100 \%$ dalam waktu $<24$ jam.
\end{abstract}

Kata kunci: kode biru, sepsis 
Pasien kritis yang mengalami perburukan di ruang rawat selalu membutuhkan tatalaksana yang tepat dan cepat. Salah satu tatalaksana pasien dalam keadaan emergensi yaitu dengan sistem kode biru. Kode biru merupakan salah satu kode darurat yang digunakan oleh rumah sakit untuk memberitahu adanya pasien henti jantung dan paru yang membutuhkan pertolongan segera tanpa menimbulkan kepanikan di dalam dan sekitar rumah sakit. ${ }^{1}$

American Heart Association (AHA) merekomendasikan suatu instrumen untuk memantau rekam medis pasien lebih mendalam sehingga dapat mentukan tindakan pertolongan yang tepat, yaitu early warning system (EWS). Early warning system dapat memrediksikan kejadian henti jantung dan napas dalam 48 jam. Penelitian di New Zealand menyatakan bahwa penerapan EWS di rumah sakit dapat menurunkan kejadian henti jantung dan paru secara bermakna. Di beberapa rumah sakit di Indonesia, penerapan EWS belum terlaksana dengan baik dikarenakan tindak lanjut setelah penilaian EWS belum sesuai dengan prosedurnya. ${ }^{2}$

Sepsis merupakan respon inflamasi dari infeksi berat yang dapat menyebabkan kerusakan organ hingga kematian. Syok septik merupakan bagian dari sepsis dimana mikroorganisme masuk ke dalam sirkulasi darah yang kemudian membuat sistem kardiovaskular terganggu. Tanda dan gejala syok septik seperti demam, takikardi, takipnea, atau jumlah sel darah putih yang abnormal dan hipotensi sebagai tanda adanya gangguan pada sirkulasi darah. ${ }^{3-5}$

Sepsis dan syok septik menjadi penyumbang kematian tertinggi di dunia. Surviving Sepsis Campaign 2018 (SSC) memperkenalkan suatu pedoman penanganan yaitu 1-hour bundle. Pedoman ini telah menggabungkan pedoman sebelumnya sehingga didapatkan penanganan yang lebih spesifik. Pedoman yang pertama ialah diagnostik kemudian manajemen pengobatan seperti pemberian antibiotik, resusitasi cairan dan dukungan vasopresor. ${ }^{6}$

Sepsis merupakan salah satu keadaan darurat, dengan demikian sepsis harus ditangani dengan segera setelah teridentifikasi. Untuk menilai kerusakan organ dapat digunakan Sequential Organ Failure Analysis (SOFA). ${ }^{6}$ Skor SOFA menggunakan tiga kriteria yaitu tekanan darah (TD $\leq 100 \mathrm{mmHg}$ ), laju pernapasan ( $\geq 22$ napas per menit), dan status mental $(\mathrm{GCS}<15)^{7}{ }^{7}$

Sepsis mengenai 30 juta orang di dunia setiap tahunnya dan 8 juta diantarnya meninggal dunia. Di Amerika Serikat, sepsis merupakan penyebab utama kematian. Berdasarkan penelitian, 1.7 juta orang di AS didiagnosis sepsis setiap tahunnya dan selalu meningkat. ${ }^{3}$ Di Indonesia, penelitian yang dilakukan di RSCM Jakarta pada tahun 2012 melaporkan bahwa 23 dari 84 kasus sepsis, 47,8\% dinyatakan meninggal dunia. ${ }^{8}$ Penelitian yang dilakukan di RSUP Prof. Dr. R. D. Kandou Manado mendapatkan angka kematian sepsis mencapai $65,7 \% .^{9}$

Tatalaksana pasien gawat darurat seperti sepsis sangat diperlukan agar dapat meningkatkan angka harapan hidup pasien sepsis di rumah sakit. Namun berdasarkan data yang ada ternyata angka harapan hidup tersebut masih belum tercapai. Hal ini melatarberlakangi penulis untuk mengetahui profil pasien sepsis yang dilakukan tindakan kode biru di RSUP Prof. Dr. R. D. Kandou, Manado.

\section{METODE PENELITIAN}

Penelitian ini dilakukan di RSUP Prof. Dr. R.D. Kandou, Manado. Jenis penelitian ialah observasional retrospektif. Sampel penelitian ialah pasien sepsis yang ditandai kode biru di RSUP Prof. Dr. R. D. Kandou pada data rekam medik periode Juni 2018 sampai Juli 2019. Variabel penelitian yaitu usia, jenis kelamin, diagnosis penyakit, penyakit penyerta, response time, penyebab kematian, dan angka kematian.

\section{HASIL PENELITIAN}

Hasil penelitian ini mendapatkan 198 kejadian kode biru di RSUP Prof. Dr. R. D. Kandou pada data rekam medik periode Juni 2018 sampai Juli 2019; 34 di antaranya ialah kejadian kode biru dengan sepsis. 
Tabel 1 menunjukkan distribusi jumlah dan persentase kode biru pada pasien sepsis berdasarkan data demografis. Berdasarkan kelompok usia 7-23 tahun didapatkan sebanyak 2 orang (6\%), kelompok usia 24-33 tahun sebanyak 3 orang (9\%), kelompok usia 34-49 tahun sebanyak 5 orang (15\%) dan kelompok usia $>50$ tahun sebanyak 24 orang $(70 \%)$. Berdasarkan jenis kelamin didapatkan pasien perempuan 19 orang (56\%) dan pasien laki-laki 15 orang (44\%).

Tabel 1. Distribusi pasien berdasarkan data dermografis

\begin{tabular}{ccc}
\hline \multicolumn{1}{c}{ Variabel } & $\mathbf{N}$ & $\mathbf{\%}$ \\
\hline Usia & & \\
7-23 tahun & 2 & $6 \%$ \\
$24-33$ tahun & 3 & $9 \%$ \\
34-49 tahun & 5 & $15 \%$ \\
$>50$ tahun & 24 & $70 \%$ \\
$\quad$ Total & 34 & $100 \%$ \\
Jenis kelamin & & \\
$\quad$ Laki-laki & 15 & $44 \%$ \\
Perempuan & 19 & $56 \%$ \\
$\quad$ Total & 34 & $100 \%$ \\
\hline
\end{tabular}

Tabel 2 menunjukan distribusi jumlah dan persentase kode biru pada pasien sepsis berdasarkan diagnosis, response time, dan kematian. Berdasarkan diagnosis sepsis didapatkan 26 orang (76\%) dan syok septik 8 orang $(24 \%)$. Pada response time $<5$ menit sebanyak 33 kejadian $(97 \%)$ dan $>5$ menit didapatkan 1 kejadian (3\%). Semua pasien kode biru dengan sepsis ditemukan 34 orang $(100 \%)$ meninggal dunia.

Tabel 3 menunjukan distribusi kode biru pada pasien sepsis berdasarkan penyakit penyerta yang dibagi atas kelompokkelompok penyakit menurut ICD-10. Didapatkan penyakit infeksi sebanyak 13 orang (38\%), penyakit metabolik sebanyak 8 orang $(23 \%)$, penyakit sirkulasi sebanyak 4 orang $(12 \%)$, penyakit pernapasan 1 orang (3\%), penyakit pencernaan sebanyak 2 orang $(6 \%)$, neoplasma sebanyak 3 orang $(9 \%)$, dan penyakit sistem saluran kemih dan genital sebanyak 3 orang $(9 \%)$.
Tabel 2. Distribusi pasien berdasarkan diagnosis, response time, dan kematian

\begin{tabular}{ccc}
\hline Variabel & $\mathbf{N}$ & $\mathbf{\%}$ \\
\hline Diagnosis & & \\
Sepsis & 26 & $76 \%$ \\
Syok Septik & 8 & $24 \%$ \\
Total & 34 & $100 \%$ \\
Response time & & \\
$<5$ menit & 33 & $97 \%$ \\
$>5$ menit & 1 & $3 \%$ \\
Total & 34 & $100 \%$ \\
Kematian & & \\
$<24$ jam & 34 & $100 \%$ \\
$24-48$ jam & - & - \\
$>48$ jam & - & - \\
Total & 34 & $100 \%$ \\
\hline
\end{tabular}

Tabel 3. Distribusi pasien berdasarkan penyakit penyerta

\begin{tabular}{lcc}
\hline \multicolumn{1}{c}{ Penyakit penyerta } & N & \% \\
\hline Penyakit infeksi & 13 & $38 \%$ \\
Gangguan metabolik & 8 & $23 \%$ \\
Penyakit sirkulasi & 4 & $12 \%$ \\
Penyakit pernapasan & 1 & $3 \%$ \\
$\begin{array}{l}\text { Penyakit pencernaan } \\
\text { Neoplasma }\end{array}$ & 2 & $6 \%$ \\
$\begin{array}{l}\text { Penyakit pada sistem } \\
\text { saluran kemih dan }\end{array}$ & 3 & $9 \%$ \\
genital & 3 & $9 \%$ \\
Total & & \\
\hline
\end{tabular}

\section{BAHASAN}

Distribusi jumlah dan persentase kejadian kode biru pada pasien dengan sepsis menunjukkan bahwa usia >50 tahun merupakan sebaran terbanyak yaitu 24 orang (70\%), diikuti usia 34-49 tahun yaitu 5 orang (15\%), usia 24-33 tahun yaitu 3 orang (9\%), dan usia 7-23 tahun yaitu 2 orang (6\%) (Tabel 1).

Usia lanjut umumnya memiliki risiko terkena infeksi yang tinggi karena menurunnya sistem kekebalan tubuh. ${ }^{10}$ Menurut Starr dan Saito, ${ }^{11}$ hal ini disebabkan karena usia lanjut lebih sering menerima perawatan paliatif daripada perawatan intensif. Hasil penelitian menyatakan bahwa pasien usia lanjut dengan sepsis 26\% lebih mungkin meninggal selama seminggu pera- 
watan di rumah sakit daripada golongan usia lainnya. Hal ini sejalan dengan hasil penelitian ini yang mendapatkan usia $>50$ tahun merupakan sebaran terbanyak untuk kejadian kode biru dengan sepsis.

Hasil penelitian ini menunjukkan bahwa berdasarkan jenis kelamin, kejadian kode biru pada pasien sepsis perempuan lebih banyak yaitu 29 orang (56\%) dan pasien laki-laki 15 orang (44\%). Sampai saat ini belum ditemukan penelitian sebelumnya untuk kasus kode biru dengan sepsis di RSUP Prof. Dr. R. D. Kandou Manado. Beberapa penelitian yang dilakukan terkait dengan jenis kelamin menunjukkan bahwa laki-laki lebih cenderung terkena sepsis dibandingkan perempuan. ${ }^{9}$ Eachempati et $\mathrm{al}^{12}$ menyatakan bahwa konsentrasi hormon steroid seks pada pasien dengan sepsis mungkin merupakan mekanisme penyebab sehingga pasien lakilaki dapat memiliki angka kematian yang lebih tinggi. Berdasarkan data rekam medik pada penelitian ini dapat dilihat bahwa jumlah kejadian kode biru dengan sepsis pada perempuan lebih banyak daripada laki-laki. Namun hal ini belum dapat menyimpulkan kemaknaannya oleh karena pada penelitian ini tidak dilakukan penghitungan secara statistik.

Distribusi jumlah dan persentase kode biru pada pasien sepsis berdasarkan diagnosis sepsis yaitu sebanyak 26 orang $(76 \%)$ dan diagnosis syok septik 8 orang (24\%). Sepsis merupakan respon inflamasi dari infeksi berat yang dapat menyebabkan kerusakan organ hingga kematian. Syok septik merupakan bagian dari sepsis dimana mikroorganisme masuk ke dalam sirkulasi darah yang kemudian membuat sistem kardiovaskular terganggu. ${ }^{3-5}$ Hasil penelitian Worapratya dan Wuthisuthimethawee ${ }^{13}$ menyatakan bahwa dengan dilakukannya skrining yang direkomendasikan yaitu qSOFA, maka sepsis dapat didiagnosis lebih cepat namun pada penelitian ini skor qSOFA memiliki sensitivitas yang buruk ketika digunakan dalam keadaan darurat. ${ }^{13}$

Berdasarkan response time kode biru, didapatkan bahwa 33 pasien (97\%) ditangani dalam waktu $<5$ menit dan 1 pasien (3\%) ditangani dalam waktu $>5$ menit. Pada saat kode biru diaktifkan, tim kode biru harus segera berlari ke tempat kejadian dengan waktu maksimum 2 menit dan 5 detik. $^{14}$ Afik $^{15}$ melakukan penelitian di RS PKU Muhammadiyah Yogyakarta dan menyatakan bahwa rerata response time yang dilakukan tim kode biru dalam manajemen panggilan darurat ialah 6,09 menit dengan kelangsungan hidup setelah itu ialah $82,4 \%$ meninggal dan $17,6 \%$ di rawat di ICU. Dibandingkan penelitian tersebut dapat dilihat response time tim kode biru di RSUP Prof. Dr. R. D. Kandou Manado terbilang cukup cepat yaitu $<5$ menit untuk 33 kasus. Response time sangat berpengaruh terhadap kelangsungan hidup pasien gawat darurat di luar rumah sakit. ${ }^{11}$

Angka kematian pada pasien kode biru dengan sepsis dari keseluruhan 34 kasus (100\%) meninggal di bawah kurun waktu $<24$ jam setelah dilakukan tindakan kode biru. Kondisi darurat pada pasien sepsis mungkin dapat ditangani dengan tindakan kode biru, tetapi tidak dipungkiri dengan berbagai penyakit penyerta yang dapat merupakan peneyebab kematian sebenarnya. Penelitian Monangi et $\mathrm{al}^{1}$ menyatakan bahwa tidak efektifnya kode biru dikaitkan dengan masalah teknis dan tim terkait yang perlu diperbaiki. Bakan et $\mathrm{al}^{16}$ melakukan penelitian untuk memrediksi kematian pada pasien kode biru menggunakan skoring prognosis APACHE II dan PRISM menyatakan bahwa dengan parameter yang tersedia tidak membantu dalam memrediksi angka kematian pada prosedur kode biru.

Keberlangsungan hidup setelah dilakukan tindakan kode biru tergantung pada keparahan penyakit, jenis dan kondisi pasien. ${ }^{17}$ Berdasarkan data yang didapatkan, penyakit infeksi menjadi jumlah penyakit penyerta yang paling banyak dan didominasi dengan diagnosis pneumonia. Hasil penelitian Gennis et al ${ }^{18}$ melaporkan bahwa dari 308 pasien dengan penyakit pernapasan yang dinyatakan gawat darurat, 118 di antaranya dianggap memiliki pneumonia. Menurut Carr et al, ${ }^{19}$ pada pasien pneumonia, henti jantung dapat terjadi karena efek dari sepsis. 
Pada gangguan metabolik penyakit yangpaling sering dijumpai ialah diabetes melitus. Penyebab utama kematian pada diabetes melitus ialah henti jantung dengan beberapa faktor risiko seperti penyakit mikrovaskuler dan neuropati. ${ }^{20-21}$ Menurut Sehatzadeh, ${ }^{17}$ pasien dengan kanker memiliki tingkat kelangsungan hidup yang lebih rendah setelah dilakukan tindakan kode biru daripada pasien dengan kondisi selain kanker. Penelitian terbaru menyatakan bahwa kemungkinan lebih tinggi untuk bertahan hidup pada pasien kanker dengan perintah "jangan resusitasi". Tanio et $\mathrm{al}^{22}$ melaporkan bahwa salah satu komplikasi dari laparotomi ialah terjadi sepsis, dan di ICU RSUP Prof. Dr. R. D. Kandou Manado didapatkan sebanyak 31 kasus pada tahun 2015 sampai 2017.

\section{SIMPULAN}

Berdasarkan hasil penelitian ini dapat disimpulkan bahwa dengan response time $<5$ menit, angka kematian pasien sepsis dengan kode biru masih tetap tinggi, yaitu $100 \%$ dalam waktu $<24$ jam. Sebagian besar pasien pada penelitian ini berusia $>50$ tahun, jenis kelamin perempuan, dengan response time $<5$ menit.

Penelitian lebih lanjut dapat dilakukan dengan menggunakan uji statistik untuk mencari faktor risiko dan faktor penyebab penanganan kode biru dengan response time yang singkat tetapi belum memperlihatkan hasil yang diharapkan. Selain itu disarankan perbaikan dan peningkatan dalam pengelolaan data pasien dalam hal proses penyimpanan data rekam medik di bagian Instalasi Rekam Medik RSUP Prof. Dr. R. D. Kandou, Manado, untuk menunjang penelitian lebih lanjut yang lebih lengkap dan akurat.

\section{DAFTAR PUSTAKA}

1. Monangi S, Setlur R, Ramanathan R, Bhasin S, Dhar M. Analysis of functioning and efficiency of a code blue system in a tertiary care hospital. Saudi J Anaesth. 2018;12(2):245-9.

2. Subhan N, Giwangkencana GW, Prihartono MA, Tavianto D. Implementasi early warning score pada kejadian henti jantung di ruang perawatan RSUP Dr. Hasan Sadikin Bandung yang ditangani Tim Code Blue selama tahun 2017. Jurnal Anestesi Perioperatif. 2019;7:3341.

3. Definition of Sepsis. Available from https:// www.sepsis.org/sepsis-basics/what-issepsis/

4. Romdhoni AC. SIRS/sepsis dan syok sepsis pada penderita tumor ganas kepala dan leher. Jurnal THT-KL. 2009;2(1):4850.

5. Parrillo J. Septic shock-vasoperin, norepinephrine, and urgency. NEJM. 2008;358:954-56.

6. Wentowski C, Mewada N, Nielsen ND. Sepsis in 2018: A Review. Anaesthesia and Intensive care Medicine. 2018;20:6-13.

7. What is qSOFA? [Internet]. Available from https://qsofa.org/what.php

8. Pedoman Nasional Pelayanan Kedokteran Tata Laksana Sepsis. Keputusan Menteri Kesehatan Republik Indonesia. Nomor HK.01.07/MENKES/342/2017. 2017; p. 1-82.

9. Tambajong RN, Kumaat LT, Lalenoh D. Profil penderita sepsis di ICU RSUP Prof. Dr. R. D. Kandou Manado periode Desem-ber 2014 - November 2015. e-CliniC. 2016; 4(1):452-7.

10. Clifford KM, Dy-Boarman EA, Haase KK, Maxvill K, Pass S, Alvarez CA. Challenges with diagnosing and managing sepsis in older adults. Expert Rev Anti Infect Ther. 2016;14(2):23141.

11. Starr ME, Saito H. Sepsis in old age: review of human and animal studies. Aging Dis. 2014;5(2):126-36.

12. Eachempati SR, Hydo L, Barie PS. Genderbased differences in outcome in patients with sepsis. Arch Surg. 1999; 134(12):1342-7.

13. Worapratya $P$, Wuthisuthimethawee $P$. Septic shock in the ER: Diagnostic and managements challenges. Emerg Med. 2014;11:77-86.

14. Eroglu SE, Onur O, Urgan O, Denizbasi A, Akoglu H. Blue Code: Is it a real emergency? World J Emerg Med. 2014;5(1):20-3.

15. Afik Al. The relationship between response time and patient survival with 
emergency treatment by the Code Blue Team. Indian J Public Health Rese Dev. 2018;9(11):1803-7.

16. Bakan N, Karaoren G, Tomruk SG, Kayalar SK. Mortality in Code Blue: can APACHE II and PRISM scores be used as markers prognostication? Ulus Travma Acil Cerrahi Derg. 2018; 24(2):149-55.

17. Sehatzadeh S. Cardiopulmonary resuscitation in patients with terminal illness: an evidence-based analysis. Ont Health Technol Assess Ser. 2014;14(15):1-38.

18. Gennis P, Gallagher J, Falvo C, Baker S. Clinical criteria for the detection of pneumonia in adults: Guidelines for ordering chest roentgenograms in the Emergency Department. J Emerg Med. 1989;7(3):263-268.

19. Carr GE, Yuen TC, McConville JF, Kres JP, VandenHoek TL, Hall JB, et al.
Early cardiac arrest in patients hospitalized with pneumonia: a report from the American Heart Association`s get with the Guidelines-Resuscitation Program. Chest. 2011;141(6): 1528-36.

20. Siscovick DS, Sotoodehnia N, Rea TD, Raghunathan TE, Jouven $X$, Lemaitre RN. Type 2 diabetes mellitus and the risk of sudden cardiac arrest in the community. Rev Endocr Metab Disord. 2010;11(1):53-9.

21. Lalenoh DC, Dalimunte C. Diabetic neurophatic pain pathophysiology and pain management. Academia Anesthesiologica International. 2017;2(1):21-4.

22. Tanio PN, Lalenoh DC, Laihad ML. Profil pasien pasca laparotomi di ICU RSUP Prof. Dr. R. D. Kandou Manado periode Januari 2015 sampai Desember 2017. e-CliniC. 2018; 6(2):80-3. 